ASIMTOT: JURNAL KEPENDIDIKAN MATEMATIKA

Volume 1 Nomor 2, Juni - November 2019, halaman 127 - 132

Tersedia Daring pada https://journal.unwira.ac.id/index.php/ASIMTOT

\title{
PENERAPAN INTEGRAL NUMERIK DALAM MENGHITUNG LUAS DAERAH TIDAK BERATURAN
}

\section{NUMERICAL INTEGRAL APPLICATION IN CALCULATING THE AREA OF REGIONAL NO REGULATIONS}

Yafet K. Pandu

Universitas Sanata Dharma

panduyafet@gmail.com

\begin{abstract}
Abstrak: Dalam kehidupan sehari - hari, maka akan ditemukan banyak daerah. Ada daerah yang beraturan dan ada daerah yang tidak beraturan. Daerah yang beraturan dapat dengan mudah untuk mencari luas daerahnya dikarenakan hanya menggunakan rumus yang berlaku pada daerah tersebut, sedangkan pada daerah tidak beraturan akan sangat sulit untuk menentukan luasnya dikarenakan tidak ada rumus baku untuk menentukan luasnya. Untuk daerah yang tidak beraturan, maka ada daerah yang dibatasi sebuah fungsi dan fungsinya sudah diketahui, maka akan digunakan perhitungan integral secara biasa. Akan tetapi apabila daerah yang tidak beraturan tersebut tidak diketahui daerah yang membatasinya, maka akan sulit dalam menentukan luas daerahnya tersebut. Salah satu cara yang dapat digunakan, yaitu dengan menggunakan integrasi numerik, di mana digunakan metode segiempat (rectangle rule) dikarenakan hanya memerlukan titik - titik koordinat $\left(x_{n}, y_{n}\right)$, di mana menyatakan panjang dan lebar dari sebuah segiempat dengan $n$ menyatakan jumlahnya pias yang berbentuk segiempat.
\end{abstract}

Kata Kunci: Metode Segitiga, Luas Daerah, Integral

Abstract: In daily life, many areas will be found. There are irregular regions and there are irregular regions. Irregular regions can easily find the area because they only use the formula that applies to the area, whereas in irregular regions it will be very difficult to determine the extent because there is no standard formula to determine its area. For irregular regions, then there are areas that are restricted to a function and its functions are known, then regular integrals will be used. However, if the irregular region is not known the area that borders it, it will be difficult to determine the area. One method that can be used, namely by using numerical integration, where the rectangle rule is used because it only requires coordinate points $\left(x_{n}, y_{n}\right)$, where denotes the length and width of a quadrilateral with n expressing the number of rectangles.

Keywords: Triangle Method, Integral

Cara Sitasi: Pandu, K. Y., (2019). Penerapan Integral Numerik Dalam Menghitung Luas Daerah Tidak Beraturan . Asimtot: Jurnal Kependidikan Matematika, “1”(“2”), “127 - 132" 
Banyak hal yang berada di dalam kehidupan sehari - hari dapat diselesaikan dengan menggunakan model matematika, misalnya menghitung laju pertumbuhan, menghitung laju aliran air, memodelkan gelombang air laut, memodelkan proses osmosis yang terjadi dalam proses penyulingan air, serta hal - hal yang lainnya. Dalam bidang ekonomi juga dapat ditemukan mengenai cara mengoptimalkan keuntungan yang dapat diperoleh. Pada ilmu statistika, maka dapat digunakan untuk menemukan model dua hubungan atau lebih. Pada bidang fisika juga kita dapat memodelkan bagaimana caranya menentukan gaya - gaya yang bekerja dalam suatu kerangka bangunan. Selain itu, model matematika juga dapat digunakan untuk menentukan luas suatu bidang dari benda maupun volume suatu benda dengan menggunakan integral.

1. Metode Analitik

Metode ini digunakan untuk menyelesaikan suatu permasalahan matematika dengan menggunakan rumus-rumus aljabar yang telah disepakati, sehingga hasil yang diperoleh dalam metode ini dapat disebut sebagai nilai sebenarnya (nilai eksak) atau nilai real dari permasalahan tersebut sehingga tidak mempunyai kesalahan (error) dikarenakan dihitung dengan menggunakan informasi - informasi serta rumus - rumus yang telah baku.

\section{Metode Numerik}

Metode ini digunakan untuk menyelesaikan suatu permasalahan matematika dengan menggunakan teknik - teknik tertentu yang telah diformulasikan secara berulang - ulang dengan menggunakan bantuan dari komputer atau dapat diformulasikan secara manual, sehingga hasil yang diperoleh merupakan nilai pendekatan terhadap apa yang hendak dicari atau diselesaikan dalam permasalahan matematika sehingga akan memiliki nilai kesalahan (error) ketika memformulasikan teknik - teknik tersebut.
Dalam persoalan yang ditemukan di lapangan, maka akan dibentuk model matematika yang kemungkinan besar akan sangat kompleks sekali modelnya sehingga akan mungkin tidak dapat ditemukan penyelesaian terhadap permasalahan tersebut. Oleh karena itu, untuk membantu kita dalam menyelesaikan permasalahan tersebut, yaitu dengan menggunakan metode numerik yang lebih mengandalkan pada pendekatan terhadap nilai yang sebenarnya.

Demikian pula, ketika kita menentukan hasil dari suatu integral yang tidak diketahui fungsinya, maka akan sangat mungkin kesulitan akan kita hadapi dalam menyelesaikan permasalahan tersebut. Misalnya, ketika kita menentukan nilai integral dari suatu fungsi yang telah diketahui dan tidak kompleks maka akan sangat mudah bagi kita untuk menyelesaikannya. Namun apabila fungsi yang hendak kita cari tidak diketahui, maka kita tidak dapat menentukan luas daerah yang dibatasi oleh fungsi tersebut. Salah satu caranya adalah dengan menggunakan integral numerik yang akan sangat dibantu oleh bantuan komputer dikarenakan fungsinya akan ditentukan dari perhitungan secara numerik oleh program program yang ada dalam perhitungan komputer tersebut. Dalam kasus ini, maka akan ditentukan nilai dari suatu luas daerah yang tidak beraturan dengan menggunakan integral numerik.

Integrasi suatu fungsi yang dinotasikan sebagai $I=\int_{a}^{b} f(x) d x$ merupakan integral suatu fungsi $f$ terhadap variabel $x$, di mana dibatasi oleh $x=a$ sampai $x=b$. Dari persamaan tersebut, maka yang dimaksud dengan integrasi merupakan nilai total atau luasan yang dibatasi oleh fungsi $\mathrm{f}$ dan sumbu- $x$, serta antara batas $x=a$ dan $x=b$. Integral yang dihitung dengan menggunakan metode analitik dapat diselesaikan dengan mudah dikarenakan fungsi yang akan ditentukan nilainya telah ditentukan.

Namun apabila fungsi yang diketahui tersebut sulit untuk dicari, maka dapat 
digunakan metode numerik untuk dilakukan sebagai suatu pendekatan. Dalam metode numerik, maka dapat membagi luasan daerah yang akan dicari dengan membaginya ke dalam pias (strip) sehingga jumlah dari pias tersebut merupakan luas total dari daerah yang akan dicari.Triatmodjo (2016) mengemukakan bahwa dalam integral numerik, maka hitungan perkiraan tersebut dilakukan dengan mendekati fungsi yang diintegralkan dengan fungsi polinomial yang diperoleh dengan berdasarkan data yang tersedia.

\section{Metode Penelitian}

Metode segiempat (rectangle rule) merupakan salah satu metode di dalam penyelesaian integrasi numerik dalam menentukan luas suatu daerah, misalkan di sini diketahui bahwa diketahui daerah yang dibatasi oleh sebuah fungsi $f(x)$ dalam interval $[a, b]$, jika interval $[a, b]$ menjadi $n$ pias, maka satu pias dapat dilihat sebagai berikut:

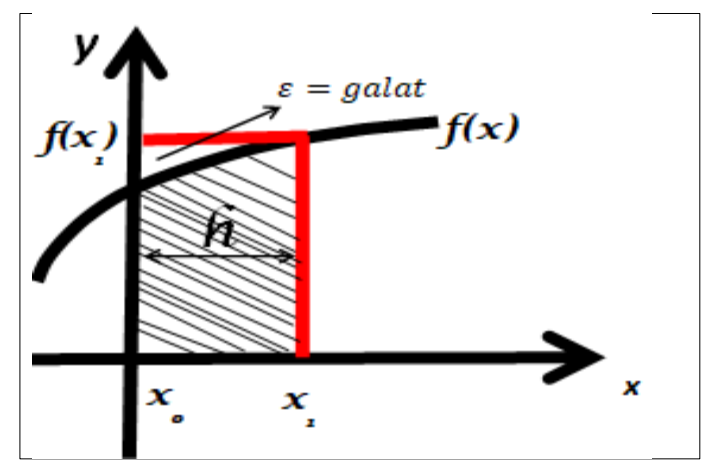

Gambar 1. Luas Satu Pias

Pastikan seluruh singkatan dan akronim didefinisikan pada saat penggunaan pertama kali untuk menghindari salah interpretasi.

Luas dari satu pias tersebut ditentukan dengan menggunakan rumus luas segiempat, yaitu $L=p \times l$, di mana panjangnya adalah $h=x_{1}-$ $x_{0}$ serta lebarnya adalah $f\left(x_{1}\right)$, yaitu sebelah kanan dari pias tersebut sehingga luas dari satu buah pias tersebut adalah $L=h f\left(x_{1}\right)$. Dari gambar 1 tersebut, maka terlihat ada ruang kosong yang ikut dihitung sebagai luas daerah yang disebut dengan kesalahan (error). Jika lebar ditentukan oleh $f\left(x_{0}\right)$ yang berada di sebelah kiri, maka luas akan ditentukan sebagai berikut: $\varepsilon=$ galat .

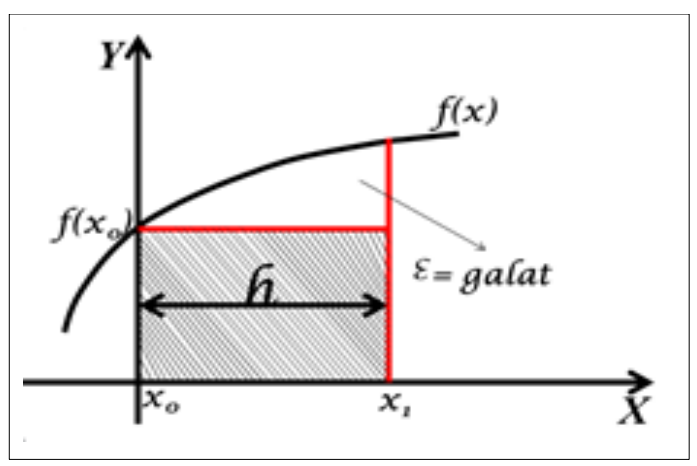

Gambar 2. Luas Pias Sebelah Kiri

Luas daerah apabila dihitung dengan menggunakan pias sebelah kiri maka $L=h f\left(x_{0}\right)$. Apabila kita menghitung luasnya dengan menggunakan pias sebelah kiri, maka akan ditemukan pula kesalahan (error) dalam perhitungannya. Oleh karena itu untuk memperkecil error tersebut, maka kedua luas yang telah diperoleh sebelumnya dijumlahkan sehingga akan diperoleh:

$$
\begin{gathered}
L \approx h f\left(x_{0}\right) \\
\frac{L \approx h f\left(x_{1}\right)}{2 L \approx h f\left(x_{0}\right)+h f\left(x_{1}\right)}+
\end{gathered}
$$

Oleh karena itu, akan diperoleh $L=$ $\int_{X_{0}}^{X_{1}} f(x) d x \approx \frac{h}{2}\left[f\left(x_{0}\right)+f\left(x_{1}\right)\right], \quad$ di mana kesalahan (error) diperoleh dengan menggunakan perhitungan sebagai berikut:

$$
\begin{aligned}
& E=-\frac{1}{12} f^{i i}(\xi)(b-a), \text { di mana } \\
& \text { nilai } f^{i i}(\xi)=\frac{f^{i}(b)-f^{i}(a)}{b-a}
\end{aligned}
$$


Jika interval dari $[a, b]$ dibagi menjadi $n$ buah pias yang sama, maka luas daerah di bawah kurva $f(x)$ menurut rectangle rule adalah:

$$
\begin{aligned}
L=\int_{a}^{b} f(x) d x & \\
& =\frac{h}{2}\left[f\left(x_{0}\right)+2 f\left(x_{1}\right)\right. \\
& +2 f\left(x_{2}\right)+\cdots \\
& \left.+2 f\left(x_{n-1}\right)+f\left(x_{n}\right)\right]
\end{aligned}
$$

\section{Hasil Penelitian dan Pembahasan}

\section{Masalah pertama:}

Misalkan diketahui sebuah bidang datar sebagai berikut:

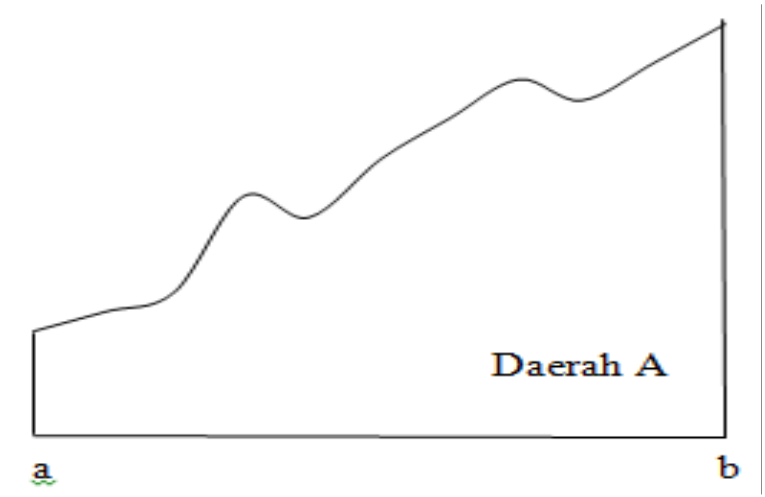

Gambar 3. Daerah A Tidak Beraturan

Daerah A tidak beraturan tersebut dibatasi oleh $a=0$ sampai $b=8,3$

Untuk mencari luas daerah A tidak beraturan tersebut, maka berikut langkah - langkahnya:

\section{Langkah pertama}

Pertama, kita membagi daerah tersebut menjadi 10 pias sehingga dari hal tersebut, maka akan diperoleh lebar setiap pias adalah $h=\frac{b-a}{10}$ dan diperoleh titik batas dari setiap pias, yaitu $x_{1}, x_{2}, x_{3}, x_{4}, x_{5}, x_{6}, x_{6}, x_{7}, x_{8}, x_{9}, x_{10} . \quad$ Dari hal tersebut, maka $h=\frac{8,3-0}{10}=0,83$ sehingga;

$$
\begin{aligned}
& x_{0}=0, x_{1}=0.83, x_{2}=1.66, x_{3} \\
& \quad=2.49, x_{4}=3.32, x_{5}=4.15, x_{6} \\
& =4.98, x_{7}=5.81, x_{8}=6.64, x_{9} \\
& =7.47, x_{10}=8.3 .
\end{aligned}
$$

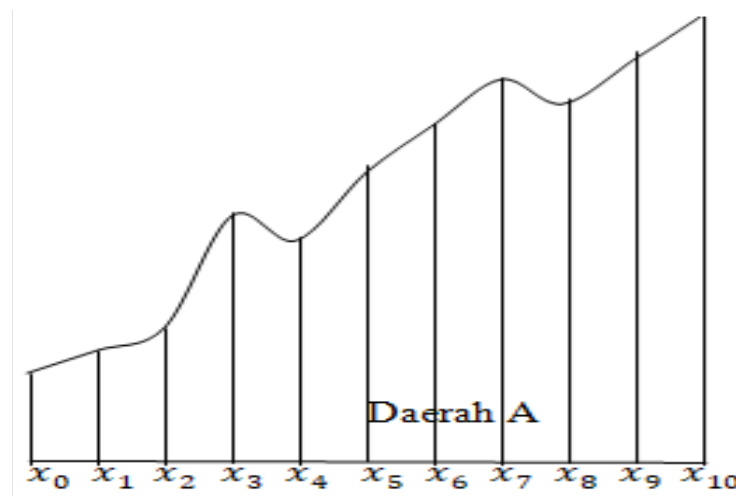

Gambar 3. Daerah A Tidak Beraturan

\section{Langkah kedua}

Kedua, kita menentukan tinggi dari setiap pias. Untuk $x_{0}$ mempunyai tinggi pias $f\left(x_{0}\right), x_{1}$ mempunyai tinggi pias $f\left(x_{1}\right), x_{2}$ mempunyai tinggi pias $f\left(x_{2}\right), x_{3}$ mempunyai tinggi pias $f\left(x_{3}\right), x_{4}$ mempunyai tinggi pias $f\left(x_{4}\right), x_{5}$ mempunyai tinggi pias $f\left(x_{5}\right), x_{6}$ mempunyai tinggi pias $f\left(x_{6}\right), x_{7}$ mempunyai tinggi pias $f\left(x_{7}\right), x_{8}$ mempunyai tinggi pias $f\left(x_{8}\right), x_{9}$ mempunyai tinggi pias $f\left(x_{9}\right)$, dan $x_{10}$ mempunyai tinggi pias $f\left(x_{10}\right)$.

Pada daerah A tersebut maka diperoleh data sebagai berikut; 
Tabel 1. Hasil Pengukuran Dalam Setiap Pias

\begin{tabular}{|c|c|c|}
\hline $\begin{array}{c}\text { No Batas } \\
\text { Pias }(n)\end{array}$ & $\begin{array}{c}\text { Batas } \\
\text { Setiap Pias } \\
\left(x_{n}\right)\end{array}$ & $\begin{array}{c}\text { Tinggi Sisi } \\
\text { Setiap Pias } \\
f\left(x_{n}\right)\end{array}$ \\
0 & $x_{0}=0$ & $f\left(x_{0}\right)=1.3$ \\
1 & $x_{1}=0.83$ & $f\left(x_{1}\right)=1.6$ \\
2 & $x_{2}=1.66$ & $f\left(x_{2}\right)=1.9$ \\
3 & $x_{3}=2.49$ & $f\left(x_{3}\right)=3.5$ \\
4 & $x_{4}=3.32$ & $f\left(x_{4}\right)=3.2$ \\
5 & $x_{5}=4.15$ & $f\left(x_{5}\right)=4.1$ \\
6 & $x_{6}=4.98$ & $f\left(x_{6}\right)=4.3$ \\
7 & $x_{7}=5.81$ & $f\left(x_{7}\right)=5.4$ \\
8 & $x_{8}=6.64$ & $f\left(x_{8}\right)=5.1$ \\
9 & $x_{9}=7.47$ & $f\left(x_{9}\right)=5.7$ \\
10 & $x_{10}=8.3$. & $f\left(x_{10}\right)=6.8$ \\
\hline
\end{tabular}

3. Langkah kedua

Dengan menggunakan metode segiempat, sehingga luas daerah A tidak beraturan tersebut adalah sebagai berikut:

$$
\begin{aligned}
L_{A}=\frac{h}{2} \times\left\{f\left(x_{0}\right)\right. & +2 f\left(x_{1}\right)+2 f\left(x_{2}\right)+2 f\left(x_{3}\right) \\
+ & 2 f\left(x_{4}\right)+2 f\left(x_{5}\right)+2 f\left(x_{6}\right) \\
+ & 2 f\left(x_{7}\right)+2 f\left(x_{8}\right)+2 f\left(x_{9}\right) \\
+ & \left.f\left(x_{10}\right)\right\} \\
=\frac{0.83}{2} \times\{1.3+ & 2 \times 1.6+2 \times 1.9+2 \times 3.5+2 \\
\times & 3.2+2 \times 4.1+2 \times 4.3+2 \\
\times & 5.4+2 \times 5.1+2 \times 5.7+6.8\} \\
=0,415 \times\{1,3 & +3,2+3,8+7+6,4+8,2 \\
& +8,6+10,8+10,2+11,4 \\
& +6,8\}=0,415 \times 77,7 \\
= & 32,2455 \mathrm{~cm}^{2}
\end{aligned}
$$

Kemudian dilakukan perhitungan dengan menggunakan excel diperoleh hasil sebagai berikut:

Tabel 2. Hasil Pengukuran Dalam Setiap Pias

\begin{tabular}{|c|c|c|}
\hline $\mathrm{Xn}$ & $\mathrm{f}(\mathrm{Xn})$ & Luas Daerah \\
\hline 0 & 1.3 & \multirow{2}{*}{32.2455} \\
\hline 0.83 & 1.6 & \\
\hline
\end{tabular}

\begin{tabular}{|l|l|}
\hline 1.66 & 1.9 \\
\hline 2.49 & 3.5 \\
\hline 3.32 & 3.2 \\
\hline 4.15 & 4.1 \\
\hline 4.98 & 4.3 \\
\hline 5.81 & 5.4 \\
\hline 6.64 & 5.1 \\
\hline 7.47 & 5.7 \\
\hline 8.3 & 6.8 \\
\hline
\end{tabular}

\section{Masalah Kedua:}

Diketahui suatu daerah seperti gambar berikut:

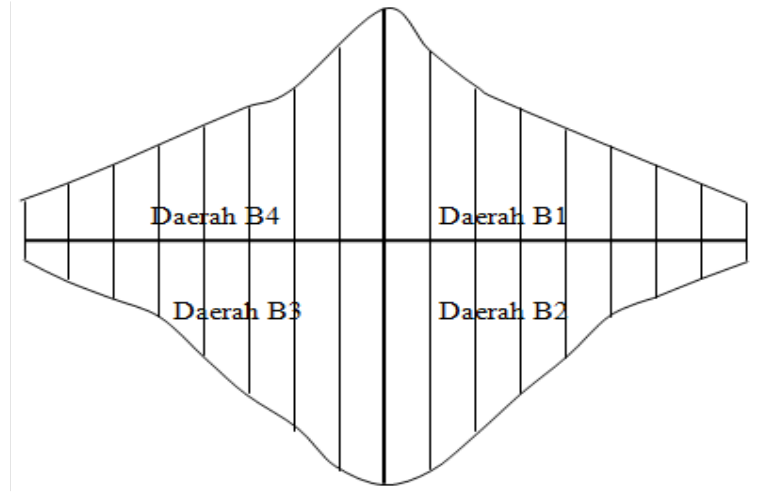

Gambar 5. Daerah B dibagi dalam 4 bagian

Berikut merupakan data dari daerah B:

\begin{tabular}{|c|c|c|c|c|c|c|c|}
\hline \multicolumn{2}{|c|}{ Daerah B1 } & \multicolumn{2}{|c|}{ Daerah B2 } & \multicolumn{2}{c|}{ Daerah B3 } & \multicolumn{2}{c|}{ Daerah B4 } \\
\hline $\mathrm{X}_{\mathrm{n}}$ & $\mathrm{f}\left(\mathrm{X}_{\mathrm{n}}\right)$ & $\mathrm{X}_{\mathrm{n}}$ & $\mathrm{f}\left(\mathrm{X}_{\mathrm{n}}\right)$ & $\mathrm{X}_{\mathrm{n}}$ & $\mathrm{f}\left(\mathrm{X}_{\mathrm{n}}\right)$ & $\mathrm{X}_{\mathrm{n}}$ & $\mathrm{f}\left(\mathrm{X}_{\mathrm{n}}\right)$ \\
\hline 0 & 3.8 & 0 & 4.1 & 0 & 4.1 & 0 & 3.8 \\
\hline 0.9125 & 3.2 & 0.9125 & 3.8 & 0.9125 & 3.8 & 0.9125 & 3.2 \\
\hline 1.825 & 2.6 & 1.825 & 3.2 & 1.825 & 3.1 & 1.825 & 2.5 \\
\hline 2.7375 & 2.2 & 2.7375 & 2.5 & 2.7375 & 2.6 & 2.7375 & 2.2 \\
\hline 3.65 & 1.9 & 3.65 & 1.9 & 3.65 & 1.9 & 3.65 & 1.9 \\
\hline 4.5625 & 1.6 & 4.5625 & 1.2 & 4.5625 & 1.2 & 4.5625 & 1.6 \\
\hline 5.475 & 1.2 & 5.475 & 0.9 & 5.475 & 1 & 5.475 & 1.2 \\
\hline 6.3875 & 0.9 & 6.3875 & 0.6 & 6.3875 & 0.7 & 6.3875 & 1.9 \\
\hline 7.3 & 0.6 & 7.3 & 0.3 & 7.3 & 0.4 & 7.3 & 1.7 \\
\hline
\end{tabular}

Gambar 5. Hasil pengukuran dalam Setiap Daerah. 
Kemudian dilakukan perhitungan dengan menggunakan excel diperoleh hasil sebagai berikut;

Tabel 3. Hasil Pengukuran dengan Excel

\begin{tabular}{|c|c|c|c|}
\hline Luas & Luas & Luas & Luas \\
Daerah & Daerah & Daerah \\
B1 & B2 & & \\
14.4175 & 14.8738 & 15.10188 & 15.74063
\end{tabular}

Kemudian untuk memperoleh luas daerah $\mathrm{B}$ tersebut diperoleh dengan menjumlahkan luas daerah B1, luas daerah B2, luas daerah B3, dan luas daerah B4 sehingga diperoleh $14,4175+14,8738+$ $15,10188+15,74063=60,13375 \mathrm{~cm}^{2}$.

\section{Simpulan dan Saran}

\section{Simpulan}

Dari pembahasan di atas, maka diperoleh bahwa untuk menghitung suatu daerah yang belum diketahui fungsinya, maka dengan menggunakan integrasi numerik yaitu metode segiempat (rectangle rule) dapat digunakan untuk menghitung luas daerah yang tidak beraturan tersebut sehingga akan membantu dalam menghitung luas suatu daerah tanpa memerlukan fungsi yang membatasi daerah tidak beraturan tersebut.

\section{Saran}

Sebagai bahan acuan bagi peneliti lain dalam menghitung suatu daerah yang belum diketahui fungsinya.

\section{Daftar Pustaka}

Triatmodjo, Bambang. 2002. Metode Numerik Dilengkapi Dengan Program

Komputer. Yogyakarta: Beta Offset Yogyakarta.

Triatmodjo, Bambang. 2016. Metode Numerik. Yogyakarta: Beta Offset Yogyakarta. 